University of Nebraska - Lincoln

DigitalCommons@University of Nebraska - Lincoln

U.S. Environmental Protection Agency Papers

U.S. Environmental Protection Agency

2011

Maternal Influences on Epigenetic Programming of the Developing Hypothalamic-Pituitary-Adrenal Axis

Curtis E. Grace

United States Environmental Protection Agency

Sung-Je Kim

United States Environmental Protection Agency

John M. Rogers

United States Environmental Protection Agency, Rogers.john@epa.gov

Follow this and additional works at: https://digitalcommons.unl.edu/usepapapers

Part of the Civil and Environmental Engineering Commons

Grace, Curtis E.; Kim, Sung-Je; and Rogers, John M., "Maternal Influences on Epigenetic Programming of the Developing Hypothalamic-Pituitary-Adrenal Axis" (2011). U.S. Environmental Protection Agency

Papers. 84.

https://digitalcommons.unl.edu/usepapapers/84

This Article is brought to you for free and open access by the U.S. Environmental Protection Agency at DigitalCommons@University of Nebraska - Lincoln. It has been accepted for inclusion in U.S. Environmental Protection Agency Papers by an authorized administrator of DigitalCommons@University of Nebraska - Lincoln. 


\title{
Maternal Influences on Epigenetic Programming of the Developing Hypothalamic-Pituitary-Adrenal Axis
}

\author{
Curtis E. Grace, Sung-Jae Kim, and John M. Rogers* \\ Toxicity Assessment Division, National Health and Environmental Effects Research Laboratory, Office of Research and Development, \\ United States Environmental Protection Agency, Research Triangle Park, North Carolina
}

Received 26 November 2010; Revised 5 February 2011; Accepted 3 March 2011

\begin{abstract}
Parental and environmental factors during the prenatal and postnatal periods permanently affect the physiology and metabolism of offspring, potentially increasing disease risk later in life. Underlying mechanisms are being elucidated, and effects on a number of organs and metabolic pathways are likely involved. In this review, we consider effects on the developing hypothalamic-pituitary-adrenal (HPA) axis, which may represent a common pathway for developmental programming. The focus is on prenatal and early postnatal development, during which the HPA axis may be programmed in a manner that affects health for a lifetime. Programming of the HPA axis involves, at least in part, epigenetic remodeling of chromatin, leading to alterations in the expression of genes in many organs and tissues involved in HPA activation and response, including the hippocampus and peripheral tissues. Examples of developmental epigenetic modifications affecting the HPA axis as well as target tissues are provided. Birth Defects Research (Part A) 91:797-805, 2011. Published 2011 by Wiley-Liss, Inc. ${ }^{\dagger}$
\end{abstract}

Key words: hypothalamus; pituitary; adrenal; epigenetics; programming

\section{INTRODUCTION}

In the past two decades, it has become increasingly clear that parental and environmental factors during the preconception to early postnatal periods have influences on the physiology and metabolism of offspring that can manifest as adverse health outcomes at any point later in life (Gluckman et al., 2007; Gluckman et al., 2008). Indeed, such changes may have consequences that extend to subsequent generations. This concept has been called the Developmental Origins of Health and Disease (DOHaD) hypothesis, and the mechanisms through which the developmental environment can alter risks of diseases such as coronary heart disease, diabetes, hypertension, obesity, and cancer later in life are beginning to be elucidated. Parental nutrition is of key importance; maternal undernutrition, overnutrition, and malnutrition have all been associated with elevated morbidity of offspring in humans and animal models. Maternal obesity and diabetes have likewise been associated with such elevated risks, as has maternal smoking. Effects on a number of organs and metabolic pathways are probably involved.
In this chapter, after providing a brief background on the $\mathrm{DOHaD}$ concept, we consider how environmental factors affect the developing hippocampus and hypothalamic-pituitary-adrenal (HPA) axis, which may represent a common pathway for developmental programming. The HPA axis, also called the stress axis, is an endocrine system that responds rapidly to changes in the environment throughout life. In this review, we will concentrate on prenatal and early postnatal development, during which the HPA axis may be programmed

\footnotetext{
"Correspondence to: John M. Rogers, MD-71, U.S. EPA, Research Triangle Park, NC 27711. E-mail: Rogers.john@epa.gov

${ }^{\dagger}$ This article is a US Government work and, as such, is in the public domain in the United States of America.

The information in this document has been subjected to review by the National Health and Environmental Effects Research Laboratory and approved for publication. Approval does not signify that the contents reflect the views of the Agency, nor does mention of trade names or commercial products constitute endorsement or recommendation for use.

Published online 7 June 2011 in Wiley Online Library (wileyonlinelibrary. com).

DOI: $10.1002 /$ bdra.20824
} 
in a much longer-term fashion, one that can affect health throughout life. Long-term programming of the HPA axis involves, at least in part, epigenetic remodeling of the chromatin in such a way as to alter the expression of genes related to HPA activity and target tissue response. Examples of developmental epigenetic modifications affecting the HPA axis are provided.

\section{BACKGROUND Human Studies}

David Barker and colleagues discovered in multiple populations that birth weight in humans correlated inversely with later risk of coronary heart disease, diabetes, and hypertension in adulthood (reviewed in Barker and Martyn, 1992; Hales and Barker, 1992; Osmond and Barker, 2000; Barker, 2004). Developmental programming of adult disease in humans has now been studied widely in the context of diverse adverse exposures. The Dutch famine of 1944-1945 has been studied by several groups. During the famine, some mothers received $<1000$ calories/day, resulting in low birth weight infants that as adults demonstrated elevated risk of glucose intolerance, altered lipid profile, coronary heart disease, stress sensitivity, and obesity (de Rooij et al., 2006; Painter et al., 2006; Roseboom et al., 2006; Lumey et al., 2009). Obese pregnant women themselves are at increased risk of being hypertensive, hyperinsulinemic, and dyslipidemic (Ramsay et al., 2002). Infants born to obese mothers have increased neonatal fat mass, elevated umbilical cord glucose and insulin concentrations, and evidence of in utero insulin resistance (Catalano et al., 2009). As adults, these children are more likely to be obese (Koupil and Toivanen, 2008) and have an elevated risk of cardiovascular disease (Forsen et al., 1997).

Maternal diabetes has similar effects on programming and is closely associated with maternal obesity (Yogev and Visser, 2009). Glucose intolerance was impaired in adolescents (Silverman et al., 1995), and arterial blood pressure (Silverman et al., 1991) and body mass index (BMI) (Silverman et al., 1995; Silverman et al., 1998) were increased later in life in offspring of diabetic mothers. Children of type 1 diabetic mothers have increased cholesterol levels, increased cholesterol/highdensity lipoprotein ratios, and increased inflammatory markers, suggesting an increased risk for metabolic and cardiovascular disease in later life (Manderson et al., 2002). In addition, they have increased BMI, skin-fold thickness, and waist circumference (Lindsay et al., 2010).

Maternal smoking has been shown to reduce birth weight and may be involved in fetal programming (Misra et al., 2005; Rogers, 2008). Children born to mothers who smoke have increased incidence of diabetes (Montgomery and Ekbom, 2002), are overweight, have increased BMI (Somm et al., 2009 for review) and are at an increased risk of hypertension. These children also have an increased heart rate and blood pressure after mild stress during sleep (Cohen et al., 2010). Interestingly, increased umbilical adrenocorticotropic hormone $(\mathrm{ACTH})$, the pituitary factor for releasing cortisol from the adrenal, has also been observed, which may connect maternal smoking to effects on HPA programming (McDonald et al., 2006).

\section{Animal Studies}

Since the emergence of the Barker hypothesis, large and small animal models of intrauterine growth retardation (IUGR) have been used to study developmental programming. Experimental treatments include maternal undernutrition (food restriction), maternal malnutrition (restriction of one or more essential nutrients, low protein being the best studied), uterine artery ligation, and glucocorticoid (primarily dexamethasone [DEX]) exposure. Maternal undernutrition (Woodall et al., 1996), protein restriction (Langley and Jackson, 1994), iron restriction (Lewis et al., 2001; Gambling et al., 2003), and uterine ligation (Jansson and Lambert, 1999) increase offspring blood pressure later in life. Other outcomes associated with these maternal treatments are altered insulin sensitivity (Ozanne et al., 1996; Sugden and Holness, 2002; Fernandez-Twinn et al., 2005), increased fat deposition (Bellinger et al., 2006), and impaired renal function (Woods et al., 2004). It is unclear whether fetal programming stems primarily from nutritional status or through endocrine alterations in the mother and fetus (or both) because prenatal glucocorticoid exposure produces metabolic effects similar to those seen in IUGR models (Benediktsson et al., 1993; Nyirenda et al., 1998; Sugden et al., 2001; Tamashiro et al., 2009).

\section{THE HPA AXIS}

\section{Glucocorticoid Programming and the HPA Axis}

Exposure to stress results in hypothalamic release of corticotropin-releasing hormone (CRH) and arginine vasopressin (AVP), which travel through the portal circulation to the anterior pituitary to stimulate release of ACTH (Fig. 1, NORMAL). The cortex of the adrenal gland is stimulated by ACTH to produce glucocorticoids, including cortisol in humans and corticosterone (CORT) in rodents. Negative feedback at the levels of the pituitary, hypothalamus, and hippocampus, which contain glucocorticoid receptors (GR), dampens the stress response and prevents damaging effects of long-term glucocorticoid exposure. The hippocampus contains a high level of GR and has a major role in inhibiting the HPA axis through feedback inhibition by glucocorticoids (Vazquez, 1998 for review). Other components of the limbic system, including the amygdala, also contain GR and play a lesser role in inhibiting the HPA axis. Peripheral tissues including the kidney, liver, and lung contain GR and exhibit metabolic and physiologic responses to changes in circulating glucocorticoids. Variants of the GR exist in a tissue specific manner and are transcribed from a single gene with multiple promoters.

\section{Effects of Maternal Stress}

Studies in which laboratory animals were undernourished during pregnancy have demonstrated effects on developmental programming. It is unclear whether this is due to fetal nutrient restriction, excess exposure of the fetus to maternal corticosteroids, or a combination of these, because undernutrition can increase maternal and fetal glucocorticoid levels (Bloomfield et al., 2004; Nunez et al., 2008). Several experiments have used different prenatal stressors to demonstrate programming effects in the absence of dietary manipulation. Maternal stress induced by foot shocks during pregnancy in rats increases both 


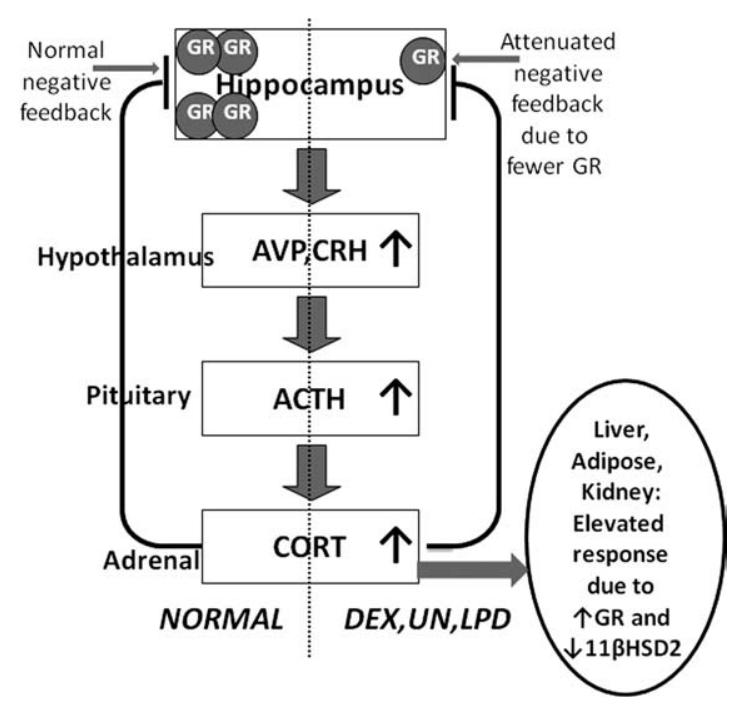

Figure 1. The offspring Hypothalamic-Pituitary-Adrenal (HPA) axis, under normal (left side) and stressed (dexamethasone [DEX] treatment, underfeeding [UN] or low-protein diet [LPD]) (right side) conditions. Under normal conditions, adrenal corticosteroids exert negative feedback on the hippocampus, which inhibits release of arginine vasopressin (AVP) and corticotrophin releasing hormone (CRH), thereby dampening the stress cascade. Abundant glucocorticoid receptors (GR) in the normal hippocampus mediate this negative feedback. In offspring of DEX-, $\mathrm{UN-}$-, or LPD-treated dams, GR in the hippocampus are fewer, attenuating the negative feedback response and prolonging the elevated release of and exposure to corticosteroids. The numbers of GR in the liver, kidney, and adipose tissue are increased, and activity of the enzyme 11ßHSD2 decreased, in offspring of DEX-, UN-, or LPD-treated dams. Increased circulating CORT, increased GR and decreased 11ßHSD2 activity can combine to enhance the glucocorticoid response in these tissues. (Adapted in part from Cottrell and Seckl, 2009).

ACTH and CORT in the fetus (Takahashi and Kalin, 1991). The serum CORT response after restraint stress in adult offspring of dams restrained during pregnancy declines more rapidly than in controls (Maccari et al., 2003), suggesting altered programming of stress reactivity. Animals prenatally exposed to maternal stress, high fat diet, or both were obese and showed impaired glucose tolerance as adults (Tamashiro et al., 2009). Further, induction of a systemic inflammatory response by IL-6 exposure during pregnancy increased maternal CORT and ACTH 4 hours after exposure; offspring were hypertensive and had altered stress reactivity as adults (Samuelsson et al., 2004).

In humans, maternal stressors such as daily hassles, trauma, or exposure to natural disasters are associated with elevated basal cortisol levels or cortisol responses to stress, as well as emotional or behavioral problems, reduced cognition, and risk of diseases such as autism and schizophrenia in their children, although long-term follow-up studies are few (O'Donnell et al., 2009 for review). Prenatal exposure to stress is also associated with lower intellectual ability in children, measured by poorer school grades (Niederhofer and Reiter, 2004) and lower scores on the Mental Scale of the Bayley Scale of Infant Development (Laplante et al., 2004). There is little evidence, however, that alteration of the HPA axis in the child is the cause of the neurobehavioral affects associated with maternal stress.

Deficits in behavior and cortical function have also been demonstrated in animal models. Prenatally stressed rats show depressive-like behaviors including increased immobility in the Porsolt swim test (Alonso et al., 1991; Frye and Wawrzycki, 2003) and increased anxiety in the elevated plus maze (Fride and Weinstock, 1988). Spatial learning deficits are also observed in adolescent mice (Bustamante et al., 2010) and adult rats (Hosseini-Sharifabad and Hadinedoushan, 2007; Wu et al., 2007) of prenatally restrained mothers.

\section{Effects of Prenatal Exogenous Glucocorticoids}

Maternal glucocorticoid administration has been used to examine long-term programming effects on offspring. The synthetic glucocorticoid DEX has been shown to reduce birth weight (Nyirenda et al., 1998) and cause adult hypertension in maternally exposed rat offspring (Benediktsson et al., 1993; Sugden et al., 2001). Basal CORT levels are elevated and hippocampal mineralocorticoid receptor (MR) and GR mRNA expression is reduced in adult rats prenatally exposed to DEX, suggesting that these receptors may be key in the programming effects (Levitt et al., 1996). In rhesus monkeys, offspring exposed to DEX prenatally have increased basal and stress-responsive cortisol levels (Uno et al., 1994). Rat dams treated with DEX or CORT early in pregnancy have offspring with reduced nephron endowment (Ortiz et al., 2001; Singh et al., 2007), which is associated with adult hypertension (Ortiz et al., 2003; Singh et al., 2007). Rat fetuses exposed to DEX during the third week of gestation were hyperglycemic, insulin resistant, and showed increased hepatic phosphoenolpyruvate carboxykinase (PEPCK, the enzyme that catalyzes the rate-limiting step in gluconeogenesis) as adults (Nyirenda et al., 1998). These findings were not due to differences in maternal care (Nyirenda et al., 2001). However, DEX-induced reduction in maternal food intake and body weight may also be associated with hypertensive programming effects (Woods and Weeks, 2005; Woods, 2006).

DEX administration in rats reduced social play in juvenile offspring, reduced acoustic startle reflex, increased acoustic startle prepulse inhibition, and increased locomotor activity after amphetamine challenge (Kleinhaus et al., 2010). Spatial learning deficits (Emgard et al., 2007) and anxiolytic behavior (Hossain et al., 2008) are observed in DEX-treated males during adulthood. CORT exposure in mice during the last week of gestation and throughout weaning also caused increased locomotor activity in the open field and depressive-like effects in the Porsolt swim test (Pechnick et al., 2006). Other studies found no DEX-induced reduction in pleasure, depression, or spatial learning deficits in offspring (Hauser et al., 2009), but, regardless of prenatal treatment, rats fostered to DEX-treated mothers had spatial learning deficits, suggesting that maternal care played a key role, because the DEX-treated mothers weighed less, ate more, and were more active outside the nest than controls (Brabham et al., 2000; Hauser et al., 2009).

\section{Role of the Placenta}

There are indications that glucocorticoid programming of offspring results from transplacental exposure to 


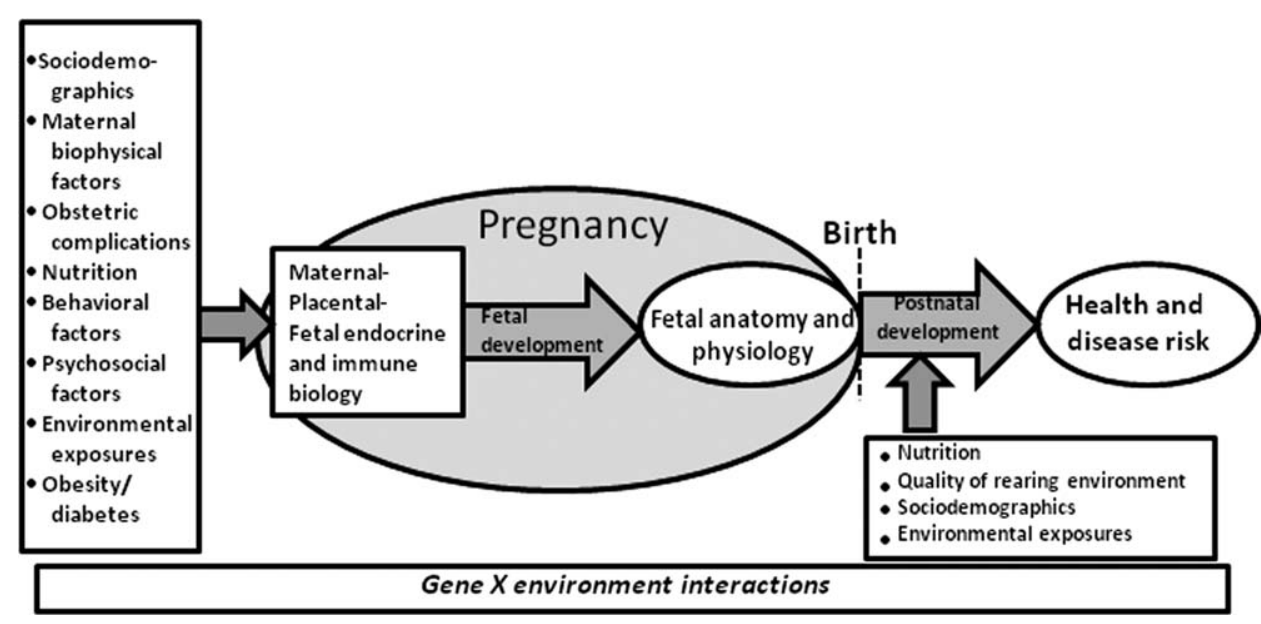

Figure 2. Maternal biologic, behavioral and environmental factors impact the intrauterine milieu, the placenta and fetal physiology. Some conditions including under- or malnutrition and stress can result in elevated maternal circulating glucocorticoids, and may decrease expression or activity of 11ßHSD2 in the placenta. Elevated glucocorticods can alter developing organs and tissues, including premature maturation and growth inhibition, leading to altered anatomy and physiology. The birth phenotype, in part, determines response to the postnatal environment, potentially resulting in increased disease risk. The genotype of the offspring also determines its interactions with the environment. (Modified after Entringer et al., 2010).

maternal steroids. Using $\left[{ }^{14} \mathrm{C}\right]-4$-corticosterone, it has been demonstrated that maternal CORT crosses the rat placenta and reaches fetal tissues, including the brain (Zarrow et al., 1970). The enzyme 11ß-hydroxysteroid dehydrogenase-2 (11ßHSD2) is highly expressed in the placenta and is involved in conversion of cortisol and CORT to inactive cortisone and 11-dehydroxycorticosterone (Brown et al., 1996; White et al., 1997). Therefore, under normal conditions, placental 11ßHSD2 minimizes fetal exposure to maternal glucocorticoids (Benediktsson et al., 1997). There is high capacity of $11 \beta$ HSD2 to inactivate glucocorticoids, so an elevated maternal glucocorticoid load does not necessarily translate to increased fetal exposure unless $11 \beta H S D 2$ is deficient or capacity is exceeded under high levels of maternal stress or disease (Benediktsson et al., 1997). Indeed, stress-induced high levels of maternal glucocorticoids can cross the placenta (Takahashi et al., 1998). DEX readily crosses the placenta and is not inactivated by 11ßHSD2, suggesting that bypassing this system may contribute to low birth weight and fetal programming of hypertension (Benediktsson et al., 1993; Nyirenda et al., 1998; Sugden et al., 2001). In further support of this idea, inhibition of 11ßHSD2 by carbenoxolone during gestation produces hypertension in adult offspring (Langley-Evans, 1997).

Maternal hormones can also stimulate production of placental $\mathrm{CRH}$, which may enter the fetal circulation and activate the fetal HPA (Majzoub and Karalis, 1999). CORT levels normally rise during late gestation in fetal rats (Dupouy et al., 1975; Boudouresque et al., 1988), likely corresponding with maturation of the fetal HPA. Therefore, stress-induced increases in fetal CORT near term may also involve the fetal HPA.

Developmental programming of physiology and metabolism most likely comprises the contributions of numerous maternal, placental, and embryo-fetal factors that together constitute the developmental environment. Along with the genetic blueprint, these factors sum to shape the phenotype of the offspring (Fig. 2).

\section{Endocrine Signaling Pathways and Mechanisms}

There are several targets and mechanisms thought to be involved in glucocorticoid programming, primarily involving GR and MR. The ontogenic timing of hippocampal GR and MR expression is species-specific (Cintra et al., 1993; Diaz et al., 1998; Noorlander et al., 2006), suggesting that windows for glucocorticoid programming differ between species. Prenatal DEX exposure decreases GR and MR expression in the adult hippocampus, which may limit negative feedback and result in increased basal CORT levels in the adult (Levitt et al., 1996).

The disruption in negative HPA feedback may contribute to adult hypertension (Seckl, 2001). Mice that are haplo-insufficient for GR exhibit increased HPA activity and are hypertensive (Michailidou et al., 2008), whereas transgenic mice carrying extra copies of the GR gene have reduced plasma CORT levels and are more resistant to restraint stress (Reichardt et al., 2000). Hypertension associated with prenatal glucocorticoid exposure may be due to reduced numbers of nephrons in the kidney, alterations in the renin-angiotensin system or alterations in baroreceptors (Seckl and Meaney, 2004; Sloboda et al., 2005 for review).

Glucocorticoids regulate key hepatic gluconeogenic enzymes. PEPCK mRNA transcription is upregulated by glucocorticoids, and this upregulation is associated with programming of diabetes-like effects (Nyirenda et al., 1998). Prenatal DEX exposure leads to increased GR expression in the adult liver and kidney, reduced $\beta$-cell mass in the pancreas, and glucose intolerance.

Glucocorticoids appear to program anxiety through changes in GR expression in the amygdala. Prenatal exposure to glucocorticoids increases CRH in the amygdala, which is associated with anxiety (Seckl and Meaney, 2004 for review) and GR overexpressing mice have increased anxiety and depressive-like behavior (Wei et al., 2004). Transgenic mice with low GR expression in the brain show reduced anxiety (Tronche et al., 1999). 


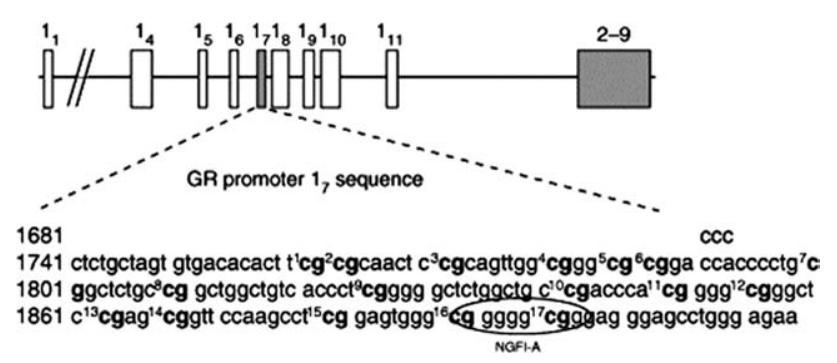

Figure 3. Structure of the rat glucocorticoid gene. The gene contains nine exons, the first of which has numerous promoter sites that are likely specific to different tissue types and glucocorticoid receptor (GR) functions therein. The promoter $1_{7}$ site has a specific binding sequence for nerve growth factor-inducible factor A (NGFI-A, see text). (From Meaney and Szyf, 2005 with permission.)

Although lower levels of GR reduce the negative feedback of the HPA, organs such as the liver and kidney, as well as adipose tissue, exhibit increased GR expression in offspring after exposure to DEX in utero (Seckl, 2001), undernutrition, or low protein diet. Combined with dampened feedback inhibition, this leads to elevation of GR-mediated activities in peripheral tissues (Fig. 2).

\section{Transgenerational Effects}

Programming effects of maternal nutrition, stress or glucocorticoid exposure can span multiple generations (reviewed in Drake and Walker, 2004; Matthews and Phillips, 2010), and the transgenerational nature of these findings suggests that epigenetic changes may be involved. Female rats born small-for-gestational age (SGA) were more likely to have SGA infants than mothers that were not born SGA (Klebanoff et al., 1997). In guinea pigs, both the F1 and F2 generations of undernourished F0 mothers showed increased thickness of septal and left ventricular walls of the heart (Bertram et al., 2008). In addition, both F1 and F2 animals had increased basal cortisol and altered HPA stress reactivity. The F1 generation of F0 dams fed a low protein diet during pregnancy and/or lactation produced an F2 generation with effects on growth and metabolism, even though the F1 mothers were fed a normal diet (Pinheiro et al., 2008). F2 offspring were hyperglycemic, hyperinsulinemic, and insulin resistant. These effects on glucose and insulin metabolism appear to be sex- and exposure period-specific (Zambrano et al., 2005). Protein restriction of F0 dams was also associated with reduced nephron number and increased blood pressure in F2 animals, but these effects were not present in the F3 generation (Harrison and Langley-Evans, 2009). DEX administration to F0 dams resulted in low birth weight, glucose intolerance, and increased liver PEPCK in the F2 generation, suggesting that excess glucocorticoid action in the F1 fetus may account for some transgenerational effects (Drake et al., 2005).

\section{Epigenetic Mechanisms of Effects on Offspring HPA axes}

Physiologic and metabolic responses of the conceptus to maternal stress have been viewed as "predictive adaptive responses" (Gluckman et al., 2005) that prepare the offspring for a postnatal environment of adversity and limited food availability. Alterations such as increased insulin sensitivity, increased adipocyte glucose transporters, reduced pancreatic $\beta$-cell mass, reduced muscle mass, and changes in arterial structure could confer an advantage in a nutritionally sparse environment. However, such adjustments are decidedly maladaptive if the postnatal environment is one of readily available, high calorie nutrition. Epigenetic adjustment of the expression of genes contributing to these adaptations during development is clearly a plausible mechanism.

Mechanisms of epigenetic regulation of gene expression include DNA methylation, changes in chromatin structure through histone modifications, and the actions of small noncoding RNAs (microRNAs, not discussed in this review) (for review of epigenetic regulation, EllisHutchings and Rogers, 2008). These mechanisms work together to affect the structure of chromatin and the accessibility of gene promoter sequences, response elements, and binding domains to their binding proteins and cofactors. Importantly, there are specific stages of development during which the epigenetic landscape is more labile than it is during adulthood.

\section{DNA Methylation}

DNA methylation is a covalent modification, primarily of cytosine residues at $\mathrm{CpG}$ dinucleotides, resulting in the formation of 5-methylcytosine (5MC). This reaction is catalyzed by DNA methyltransferases (DNMTs) a family of proteins that use S-adenosylmethionine (SAM) as the methyl donor. The enzyme DNMT-1 is a maintenance methyltransferase that preferentially uses hemimethylated DNA as a substrate and serves to maintain fidelity of the methylation pattern during DNA replication. In general, methylation in the promoter region of a gene is associated with inhibition of transcription. Methylation of the promoter serves to block access of transcription factors and other DNA binding proteins and to attract specific $5 \mathrm{MCpG}$ binding proteins that induce chromatin condensation by recruiting corepressor proteins and enzymes involved in histone modifications. Demethylation of parental DNA occurs at several points during gametogenesis, fertilization, and embryonic development. Reestablishment of DNA methylation then proceeds in the embryo, accomplished by the de novo methyltransferases, DNMT3A, DNMT3B, and DNMT3L. The availability of sufficient methyl donors is critical for the remethylation process.

\section{Histone Modifications}

Histones consist of octamers of the histone proteins H2A, H2B, H3, and H4. The octamer is wrapped by 147 base pairs (bp) of DNA to form the nucleosome. The tails of the histone proteins protrude from the nucleosomes and are subject to an array of modifications that affect the charge and conformation of the histones and availability of the DNA for transcription. Histone modifications include acetylation, methylation, poly-ADP-ribosylation, glycosylation, phosphorylation, sumoylation, and ubiquitination. The combination of histone modifications within a given cell type constitutes what has been termed the "histone code" that, in part, determines the cell-specific pattern of gene expression. Acetylation is one of the 


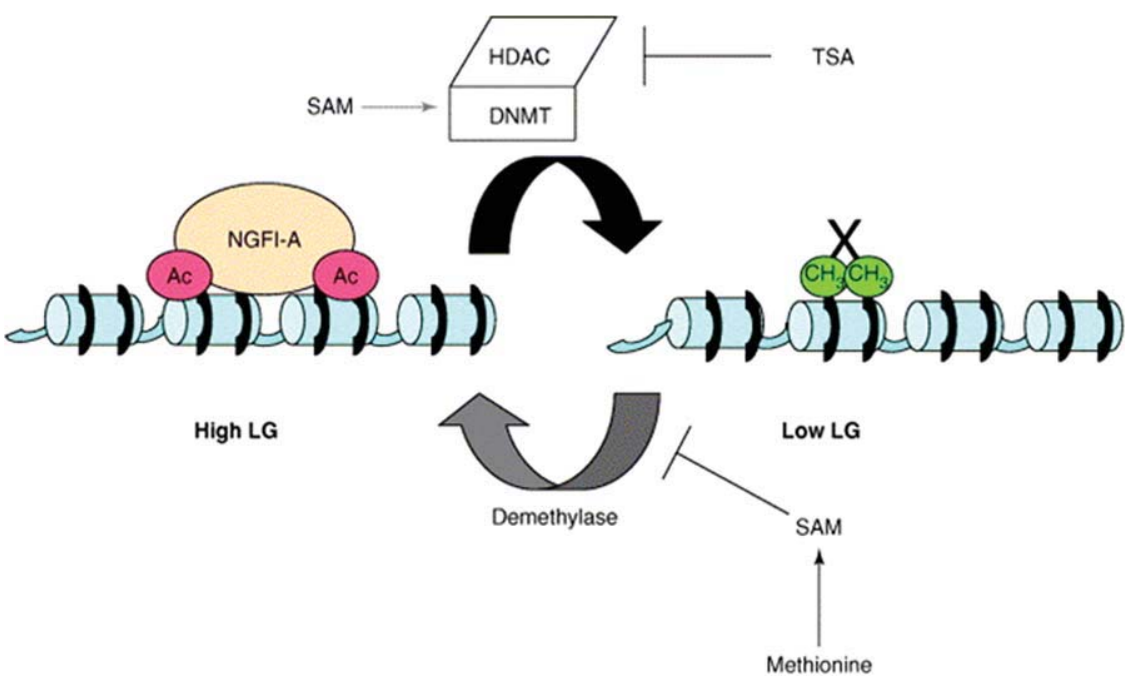

Figure 4. Maternally programmed stress responses in rat offspring are reversible and depend on glucocorticoid receptor (GR) expression. Epigenetic status of the GR promoter region is determined in part by maternal nurturing behavior in the postnatal period and is then maintained. However treatment with the histone deacetylase inhibitor, trichostatin A (TSA), increases histone acetylation and decreases methylation of the GR promoter, upregulating expression of the gene. Conversely, treatment with the methyl donor, methionine, results in hypermethylation of the GR promoter and decreased GR expression. (From Meaney and Szyf, 2005, with permission.)

common histone modifications, and acetylation of lysine 9 on histone protein $\mathrm{H} 3$ (denoted as H3K9Ac) is associated with promoter activation. Histone acetylation results from the activity of histone acetyltransferases and histone deacetylases.

\section{Epigenetic Programming}

Offspring of pregnant rats fed a diet low in methyl donors exhibited lower levels of DNA methylation and increased $\mathrm{H} 3 \mathrm{~K} 9 \mathrm{Ac}$ in promoters of genes including those for the GR and the peroxisome proliferator activator- $\alpha$ $($ PPAR- $\alpha)$. These changes were associated with increased hepatic expression of these genes in juvenile (Lillycrop et al., 2005) and adult offspring (Lillycrop et al., 2007). Folic acid supplementation during pregnancy (Lillycrop et al., 2005; Lillycrop et al., 2007; Lillycrop et al., 2008) or in the postnatal period (Burdge et al., 2009) ameliorated these effects.

One of the best examples of epigenetic programming of offspring is the relationship between maternal care and programming of the HPA axis in offspring of Long Evans rats, elucidated by Meaney, Weaver, Szyf and colleagues (for reviews, Meaney, 2001; Weaver, 2009; Meaney, 2010). Lactating Long Evans mothers display considerable variation in the degree of maternal care given to their offspring. By segregating dams into high licking and grooming (high LG) and low licking and grooming (low LG) categories, Meaney and coworkers have studied the role of early maternal care in the ontogeny of the stress response and other behaviors in offspring. Adult male offspring of high LG mothers have lower plasma ACTH and CORT concentrations in response to stress, elevated hippocampal GR mRNA, and elevated hypothalamic CRH mRNA than do male offspring of low LG dams. Variations in maternal LG are transmitted across generations, such that female offspring of high LG mothers become high LG mothers themselves, and daughters of low LG dams likewise become low LG mothers.

The GR is the central focus of the epigenetic programming of the offspring stress response by the level of maternal care. The GR is a ligand-activated transcription factor that is found in the cytoplasm and the nucleus. In the cytoplasm, the GR exists as a multiprotein complex that contains chaperone (HSP90) and cochaperone (p23) proteins. On binding to CORT, the GR undergoes a conformational change, homodimerizes and translocates to the nucleus. The activated GR binds to specific elements in the DNA, and also binds other cofactors in a cell typespecific manner. Different cofactors present in different cell types lead to cell type-specific actions induced by the GR. For example, activation of the GR in the fetal lung leads to surfactant production, whereas GR activation in the forebrain leads to decreased neurogenesis and decreased synaptic plasticity. The structure of the GR gene is similar in humans and rats. The rat GR gene consists of nine exons (Fig. 3). Exons 2-9 encode multiple variants of the GR. Exon 1 contains a number of promoters that are used in a cell type-specific manner. For example, the exon $1_{7}$ promoter binds the transcription factor nerve growth factor-inducible factor A (NGFI-A) (Crosby et al., 1991).

Hippocampal GR regulates the HPA axis through a negative feedback loop. Higher levels of GR in the hippocampus are associated with a dampened stress response (Fig. 2). Expression of the GR gene in the hippocampus is inversely related to the degree of methylation in the GR $1_{7}$ promoter region. The binding site for NGFI-A within the $1_{7}$ promoter, is methylated to a greater extent in hippocampi from low LG offspring than it is in hippocampi from high LG offspring. Lower methylation of the NGFI-A binding site allows for more binding of NGFI-A, and hence higher levels of GR transcription. Differences in degree of promoter methylation between high LG offspring and low LG offspring appear after birth and 
persist through weaning into adulthood. The epigenome of high LG and low LG offspring can be altered by treatment with trichostatin-A (TSA), a histone deacetylase inhibitor that also promotes demethylation of DNA. Adult offspring of low LG mothers lose the low LG phenotype when treated with TSA (Weaver et al., 2004; Weaver et al., 2006). This treatment specifically targets the methylation of the GR $1_{7}$ promoter region. Conversely, administration of the methyl donor methionine, which promotes methylation, causes offspring of high LG mothers to become more stress reactive and have lower levels of hippocampal GR mRNA (Weaver et al., 2005). Aspects of the control of GR gene expression are depicted in Figure 4.

Interestingly, female offspring of high LG and low LG mothers diverge at the level of ER- $\alpha$ gene expression in the median preoptic area of the brain, with long-term suppression of ER- $\alpha$ gene expression in low LG female offspring. Similar to the GR promoter, increased levels of DNA methylation of the ER- $\alpha$ promoter region of low LG female offspring leads to lower expression of the ER$\alpha$ gene.

Another model of epigenetic shaping of the stress response uses repeated isolation of mouse pups from their mother during the first 10 days of life (Murgatroyd et al., 2009). In this case the epigenetic changes observed were at another level of the HPA axis, namely the AVP gene, which codes for arginine vasopressin in the paraventricular nucleus of the hypothalamus. Maternal deprivation was associated with hypomethylation of a binding site for MeCP2. Hypomethylation of this region was associated with persistent upregulation of AVP gene expression and hyperactivation of the HPA axis for at least 1 year. These offspring also exhibited reduced stress-coping ability and memory deficits. The hypomethylation of the MeCP2 binding site develops gradually. The first stage is the phosphorylation of MeCP2, which eliminates its binding affinity for the $A V P$ binding site. In the absence of MeCP2 binding, methylation of the AVP binding site is inadequately maintained, leading to enhanced transcription of the gene. Once MeCP2 is dephosphorylated, the decreased methylation of the binding site results in decreased binding of $\mathrm{MeCP} 2$, so increased transcription is maintained despite reversion of MeCP2 to the dephosphorylated form.

\section{Epigenetic Control of 11ßHSD2}

Earlier in this review, we discussed glucocorticoid metabolism by $11 \beta H S D 2$ in the placenta and peripheral tissues. CPG islands covering the promoter and exon 1 of the gene HSD11B2, which encodes $11 \beta H S D 2$, are heavily methylated in tissues with low expression but not those exhibiting high expression of HSD11B2 (Alikhani-Koopaei et al., 2004). In the kidney, where the gene is highly expressed, reduced activity of the enzyme can cause hypertension through overactivation of the MR by CORT, leading to renal sodium retention and a salt-sensitive increase in blood pressure (Ferrari and Krozowski, 2000). Indeed, in humans elevated HSD11B2 promoter methylation is associated with hypertension (Friso et al., 2008). In an IUGR rat model of hypertension, persistently decreased renal 11ßHSD2 mRNA and protein levels were associated with decreased binding of the transcription factors SP1, NF- $\kappa$ B p65, NF- $\kappa$ B p50, and Egr-1 (Baserga et al., 2010). Also observed were increased DNA methylation and modified patterns of methylation in the promoter and decreased trimethylation of H3K36 in exon 5 of the HSD11B2 gene. These changes were associated with decreased transcription of the gene, possibly contributing to the elevated blood pressure observed in these offspring.

\section{CONCLUSIONS}

The stress response is an essential endocrine mechanism for survival and is controlled by the HPA axis. Elevated responses to stress are adaptive, increasing the availability of energy substrates and heightening the "fight or flight response." Although this may have obvious benefits in times of crisis, chronically elevated stress response can predispose individuals to chronic diseases including metabolic derangements and psychologic illnesses. The HPA axis, as well as the hippocampus and the responsiveness of peripheral tissues to glucocorticoids, appear to be tuned in response to the developmental environment (pre- and postnatal) as a predictive adaptive response, but this may be maladaptive if the environment later in life is dissonant with that experienced during development. Functioning of the HPA and set points for the stress response are, in part, determined by the epigenome, as exemplified here by the epigenetic determination of the expression of the genes for the GR, 11ßHSD2, and AVP. Although epigenetic remodeling of the chromatin is not the only means to achieving developmental programming, these examples show the elegant way in which the epigenome can define physiologic and metabolic responses for a lifetime.

\section{REFERENCES}

Alikhani-Koopaei R, Fouladkou F, Frey FJ, et al. 2004. Epigenetic regulation of 11 beta-hydroxysteroid dehydrogenase type 2 expression. J Clin Invest 114(8):1146-1157.

Alonso SJ, Arevalo R, Afonso D, et al. 1991. Effects of maternal stress during pregnancy on forced swimming test behavior of the offspring. Physiol Behav 50(3):511-517.

Barker DJ. 2004. The developmental origins of adult disease. J Am Coll Nutr 23(6 Suppl):588S-595S.

Barker DJ, Martyn CN. 1992. The maternal and fetal origins of cardiovascular disease. J Epidemiol Community Health 46(1):8-11.

Baserga M, Kaur R, Hale MA, et al. 2010. Fetal growth restriction alters transcription factor binding and epigenetic mechanisms of renal 11beta-hydroxysteroid dehydrogenase type 2 in a sex-specific manner. Am J Physiol Regul Integr Comp Physiol 299(1):R334-R342.

Bellinger L, Sculley DV, Langley-Evans SC. 2006. Exposure to undernutrition in fetal life determines fat distribution, locomotor activity and food intake in ageing rats. Int J Obes (Lond) 30(5):729-738.

Benediktsson R, Calder AA, Edwards CR, et al. 1997. Placental 11 betahydroxysteroid dehydrogenase: a key regulator of fetal glucocorticoid exposure. Clin Endocrinol (Oxf) 46(2):161-166.

Benediktsson R, Lindsay RS, Noble J, et al. 1993. Glucocorticoid exposure in utero: new model for adult hypertension. Lancet 341(8841):339341.

Bertram C, Khan O, Ohri S, et al. 2008. Transgenerational effects of prenatal nutrient restriction on cardiovascular and hypothalamic-pituitaryadrenal function. J Physiol 586(8):2217-2229.

Bloomfield FH, Oliver MH, Hawkins P, et al. 2004. Periconceptional undernutrition in sheep accelerates maturation of the fetal hypothalamic-pituitary-adrenal axis in late gestation. Endocrinology 145(9):4278-4285.

Boudouresque F, Guillaume V, Grino M, et al. 1988. Maturation of the pituitary-adrenal function in rat fetuses. Neuroendocrinology 48(4):417422.

Brabham T, Phelka A, Zimmer C, et al. 2000. Effects of prenatal dexamethasone on spatial learning and response to stress is influenced by maternal factors. Am J Physiol Regul Integr Comp Physiol 279(5): R1899-R1909 
Brown RW, Chapman KE, Kotelevtsev Y, et al. 1996. Cloning and production of antisera to human placental 11 beta-hydroxysteroid dehydrogenase type 2. Biochem J 313 (Pt 3):1007-1017.

Burdge GC, Lillycrop KA, Phillips ES, et al. 2009. Folic acid supplementation during the juvenile-pubertal period in rats modifies the phenotype and epigenotype induced by prenatal nutrition. J Nutr 139(6):1054-1060.

Bustamante C, Bilbao P, Contreras W, et al. 2010. Effects of prenatal stress and exercise on dentate granule cells maturation and spatial memory in adolescent mice. Int J Dev Neurosci 28(7):605-609.

Catalano PM, Presley L, Minium J, et al. 2009. Fetuses of obese mothers develop insulin resistance in utero. Diabetes Care 32(6):1076-1080.

Cintra A, Solfrini V, Bunnemann B, et al. 1993. Prenatal development of glucocorticoid receptor gene expression and immunoreactivity in the rat brain and pituitary gland: a combined in situ hybridization and immunocytochemical analysis. Neuroendocrinology 57(6):1133-1147.

Cohen G, Jeffery H, Lagercrantz H, et al. 2010. Long-term reprogramming of cardiovascular function in infants of active smokers. Hypertension 55(3):722-728.

Cottrell EC, Seckl JR. 2009. Prenatal stress, glucocorticoids and the programming of adult disease. Front Behav Neurosci 3:19.

Crosby SD, Puetz JJ, Simburger KS, et al. 1991. The early response gene NGFI-C encodes a zinc finger transcriptional activator and is a member of the GCGGGGGCG (GSG) element-binding protein family. Mol Cell Biol 11(8):3835-3841.

de Rooij SR, Painter RC, Phillips DI, et al. 2006. Impaired insulin secretion after prenatal exposure to the Dutch famine. Diabetes Care 29(8):1897-1901

Diaz R, Brown RW, Seckl JR, et al. 1998. Distinct ontogeny of glucocorticoid and mineralocorticoid receptor and 11beta-hydroxysteroid dehydrogenase types I and II mRNAs in the fetal rat brain suggest a complex control of glucocorticoid actions. J Neurosci 18(7):2570-2580.

Drake AJ, Walker BR. 2004. The intergenerational effects of fetal programming: non-genomic mechanisms for the inheritance of low birth weight and cardiovascular risk. J Endocrinol 180(1):1-16.

Drake AJ, Walker BR, Seckl JR, et al. 2005. Intergenerational consequences of fetal programming by in utero exposure to glucocorticoids in rats. Am J Physiol Regul Integr Comp Physiol 288(1):R34-R38.

Dupouy JP, Coffigny H, Magre S, et al. 1975. Maternal and foetal corticosterone levels during late pregnancy in rats. J Endocrinol 65(3):347-352.

Ellis-Hutchings R, Rogers JM. 2008. Epigenetic Mechanisms-Role of DNA methylation and histone acetylation. In: D. Hansen and B. Abbott E, editors. Developmental toxicology. 3rd ed. New York: Informa Healthcare.

Emgard M, Paradisi M, Pirondi S, et al. 2007. Prenatal glucocorticoid exposure affects learning and vulnerability of cholinergic neurons. Neurobiol Aging 28(1):112-121.

Entringer S, Buss C, Wadhwa PD. 2010. Prenatal stress and developmental programming of human health and disease risk: concepts and integration of empirical findings. Curr Opin Endocrinol Diabetes Obes 17:507-516.

Fernandez-Twinn DS, Wayman A, Ekizoglou S, et al. 2005. Maternal protein restriction leads to hyperinsulinemia and reduced insulinsignaling protein expression in 21-mo-old female rat offspring. Am J Physiol Regul Integr Comp Physiol 288(2):R368-R373.

Ferrari P, Krozowski Z. 2000. Role of the 11beta-hydroxysteroid dehydrogenase type 2 in blood pressure regulation. Kidney Int 57(4):1374-1381.

Forsen T, Eriksson JG, Tuomilehto J, et al. 1997. Mother's weight in pregnancy and coronary heart disease in a cohort of Finnish men: follow up study. BMJ 315(7112):837-840.

Fride E, Weinstock M. 1988. Prenatal stress increases anxiety related behavior and alters cerebral lateralization of dopamine activity. Life Sci 42(10):1059-1065.

Friso S, Pizzolo F, Choi SW, et al. 2008. Epigenetic control of 11 betahydroxysteroid dehydrogenase 2 gene promoter is related to human hypertension. Atherosclerosis 199(2):323-327.

Frye CA, Wawrzycki J. 2003. Effect of prenatal stress and gonadal hormone condition on depressive behaviors of female and male rats. Horm Behav 44(4):319-326.

Gambling L, Dunford S, Wallace DI, et al. 2003. Iron deficiency during pregnancy affects postnatal blood pressure in the rat. J Physiol 552(Pt 2):603-610.

Gluckman PD, Hanson MA, Beedle AS, et al. 2007. Early life events and their consequences for later disease: a life history and evolutionary perspective. Am J Hum Biol 19(1):1-19.

Gluckman PD, Hanson MA, Cooper C, et al. 2008. Effect of in utero and early-life conditions on adult health and disease. $\mathrm{N}$ Engl J Med 359(1):61-73.

Gluckman PD, Hanson MA, Spencer HG, et al. 2005. Predictive adaptive responses and human evolution. Trends Ecol Evol 20(10):527-533.

Hales CN, Barker DJ. 1992. Type 2 (non-insulin-dependent) diabetes mellitus: the thrifty phenotype hypothesis. Diabetologia 35(7):595-601.
Harrison M, Langley-Evans SC. 2009. Intergenerational programming of impaired nephrogenesis and hypertension in rats following maternal protein restriction during pregnancy. Br J Nutr 101(7):1020-1030.

Hauser J, Feldon J, Pryce CR, et al. 2009. Direct and dam-mediated effects of prenatal dexamethasone on emotionality, cognition and HPA axis in adult Wistar rats. Horm Behav 56(4):364-375.

Hossain A, Hajman K, Charitidi K, et al. 2008. Prenatal dexamethasone impairs behavior and the activation of the BDNF exon IV promoter in the paraventricular nucleus in adult offspring. Endocrinology 149(12):6356-6365.

Hosseini-Sharifabad M, Hadinedoushan H. 2007. Prenatal stress induces learning deficits and is associated with a decrease in granules and CA3 cell dendritic tree size in rat hippocampus. Anat Sci Int 82(4):211-217.

Jansson T, Lambert GW. 1999. Effect of intrauterine growth restriction on blood pressure, glucose tolerance and sympathetic nervous system activity in the rat at 3-4 months of age. J Hypertens 17(9):1239-1248.

Klebanoff MA, Schulsinger C, Mednick BR, et al. 1997. Preterm and small-for-gestational-age birth across generations. Am J Obstet Gynecol 176(3):521-526.

Kleinhaus K, Steinfeld S, Balaban J, et al. 2010. Effects of excessive glucocorticoid receptor stimulation during early gestation on psychomotor and social behavior in the rat. Dev Psychobiol 52(2):121-132.

Koupil I, Toivanen P. 2008. Social and early-life determinants of overweight and obesity in 18-year-old Swedish men. Int J Obes (Lond) 32(1):73-81.

Langley-Evans SC. 1997. Maternal carbenoxolone treatment lowers birthweight and induces hypertension in the offspring of rats fed a protein-replete diet. Clin Sci (Lond) 93(5):423-429.

Langley SC, Jackson AA. 1994. Increased systolic blood pressure in adult rats induced by fetal exposure to maternal low protein diets. Clin Sci (Lond) 86(2):217-222; discussion 121.

Laplante DP, Barr RG, Brunet A, et al. 2004. Stress during pregnancy affects general intellectual and language functioning in human toddlers. Pediatr Res 56(3):400-410.

Levitt NS, Lindsay RS, Holmes MC, et al. 1996. Dexamethasone in the last week of pregnancy attenuates hippocampal glucocorticoid receptor gene expression and elevates blood pressure in the adult offspring in the rat. Neuroendocrinology 64(6):412-418.

Lewis RM, Petry CJ, Ozanne SE, et al. 2001. Effects of maternal iron restriction in the rat on blood pressure, glucose tolerance, and serum lipids in the 3-month-old offspring. Metabolism 50(5):562-567.

Lillycrop KA, Phillips ES, Jackson AA, et al. 2005. Dietary protein restriction of pregnant rats induces and folic acid supplementation prevents epigenetic modification of hepatic gene expression in the offspring. J Nutr 135(6):1382-1386.

Lillycrop KA, Phillips ES, Torrens C, et al. 2008. Feeding pregnant rats a protein-restricted diet persistently alters the methylation of specific cytosines in the hepatic PPAR alpha promoter of the offspring. Br J Nutr 100(2):278-282.

Lillycrop KA, Slater-Jefferies JL, Hanson MA, et al. 2007. Induction of altered epigenetic regulation of the hepatic glucocorticoid receptor in the offspring of rats fed a protein-restricted diet during pregnancy suggests that reduced DNA methyltransferase-1 expression is involved in impaired DNA methylation and changes in histone modifications. Br J Nutr 97(6):1064-1073.

Lindsay RS, Nelson SM, Walker JD, et al. 2010. Programming of adiposity in offspring of mothers with type 1 diabetes at age 7 years. Diabetes Care 33(5):1080-1085

Lumey LH, Stein AD, Kahn HS, et al. 2009. Lipid profiles in middle-aged men and women after famine exposure during gestation: the Dutch Hunger Winter Families Study. Am J Clin Nutr 89(6):1737-1743.

Maccari S, Darnaudery M, Morley-Fletcher S, et al. 2003. Prenatal stress and long-term consequences: implications of glucocorticoid hormones. Neurosci Biobehav Rev 27(1-2):119-127.

Majzoub JA, Karalis KP. 1999. Placental corticotropin-releasing hormone: function and regulation. Am J Obstet Gynecol 180(1 Pt 3):S242-S246.

Manderson JG, Mullan B, Patterson CC, et al. 2002. Cardiovascular and metabolic abnormalities in the offspring of diabetic pregnancy. Diabetologia 45(7):991-996.

Matthews SG, Phillips DI. 2010. Minireview: transgenerational inheritance of the stress response: a new frontier in stress research. Endocrinology 151(1):7-13.

McDonald SD, Walker M, Perkins SL, et al. 2006. The effect of tobacco exposure on the fetal hypothalamic-pituitary-adrenal axis. BJOG 113(11):1289-1295.

Meaney MJ. 2001. Maternal care, gene expression, and the transmission of individual differences in stress reactivity across generations. Annu Rev Neurosci 24:1161-1192.

Meaney MJ. 2010. Epigenetics and the biological definition of gene $\times$ environment interactions. Child Dev 81(1):41-79. 
Meaney MJ, Szyf M. 2005. Maternal care as a model for experience-dependent chromatin plasticity? Trends Neurosci 28(9):456-463.

Michailidou Z, Carter RN, Marshall E, et al. 2008. Glucocorticoid receptor haploinsufficiency causes hypertension and attenuates hypothalamicpituitary-adrenal axis and blood pressure adaptions to high-fat diet. FASEB J 22(11):3896-3907.

Misra DP, Astone N, Lynch CD, et al. 2005. Maternal smoking and birth weight: interaction with parity and mother's own in utero exposure to smoking. Epidemiology 16(3):288-293.

Montgomery SM, Ekbom A. 2002. Smoking during pregnancy and diabetes mellitus in a British longitudinal birth cohort. BMJ 324(7328):2627

Murgatroyd C, Patchev AV, Wu Y, et al. 2009. Dynamic DNA methylation programs persistent adverse effects of early-life stress. Nat Neurosci 12(12):1559-1566.

Niederhofer H, Reiter A. 2004. Prenatal maternal stress, prenatal fetal movements and perinatal temperament factors influence behavior and school marks at the age of 6 years. Fetal Diagn Ther 19(2):160162.

Noorlander CW, De Graan PN, Middeldorp J, et al. 2006. Ontogeny of hippocampal corticosteroid receptors: effects of antenatal glucocorticoids in human and mouse. J Comp Neurol 499(6):924-932.

Nunez H, Ruiz S, Soto-Moyano R, et al. 2008. Fetal undernutrition induces overexpression of CRH mRNA and CRH protein in hypothalamus and increases $\mathrm{CRH}$ and corticosterone in plasma during postnatal life in the rat. Neurosci Lett 448(1):115-119.

Nyirenda MJ, Lindsay RS, Kenyon CJ, et al. 1998. Glucocorticoid exposure in late gestation permanently programs rat hepatic phosphoenolpyruvate carboxykinase and glucocorticoid receptor expression and causes glucose intolerance in adult offspring. J Clin Invest 101(10):21742181

Nyirenda MJ, Welberg LA, Seckl JR, et al. 2001. Programming hyperglycaemia in the rat through prenatal exposure to glucocorticoids-fetal effect or maternal influence? J Endocrinol 170(3):653-660.

O'Donnell K, O'Connor TG, Glover V, et al. 2009. Prenatal stress and neurodevelopment of the child: focus on the HPA axis and role of the placenta. Dev Neurosci 31(4):285-292.

Ortiz LA, Quan A, Weinberg A, et al. 2001. Effect of prenatal dexamethasone on rat renal development. Kidney Int 59(5):1663-1669.

Ortiz LA, Quan A, Zarzar F, et al. 2003. Prenatal dexamethasone programs hypertension and renal injury in the rat. Hypertension 41(2):328-334.

Osmond C, Barker DJ. 2000. Fetal, infant, and childhood growth are predictors of coronary heart disease, diabetes, and hypertension in adult men and women. Environ Health Perspect 108 Suppl 3:545-553.

Ozanne SE, Wang CL, Coleman N, Smith GD. 1996. Altered muscle insulin sensitivity in the male offspring of protein-malnourished rats. Am J Physiol 271(6 Pt 1):E1128-1134.

Painter RC, de Rooij SR, Bossuyt PM, et al. 2006. Early onset of coronary artery disease after prenatal exposure to the Dutch famine. Am J Clin Nutr 84(2):322-327; quiz 466-327.

Pechnick RN, Kariagina A, Hartvig E, et al. 2006. Developmental exposure to corticosterone: behavioral changes and differential effects on leukemia inhibitory factor (LIF) and corticotropin-releasing hormone (CRH) gene expression in the mouse. Psychopharmacology (Berl) 185(1):76-83.

Pinheiro AR, Salvucci ID, Aguila MB, et al. 2008. Protein restriction during gestation and/or lactation causes adverse transgenerational effects on biometry and glucose metabolism in F1 and F2 progenies of rats. Clin Sci (Lond) 114(5):381-392.

Ramsay JE, Ferrell WR, Crawford L, et al. 2002. Maternal obesity is associated with dysregulation of metabolic, vascular, and inflammatory pathways. J Clin Endocrinol Metab 87(9):4231-4237.

Reichardt HM, Umland T, Bauer A, et al. 2000. Mice with an increased glucocorticoid receptor gene dosage show enhanced resistance to stress and endotoxic shock. Mol Cell Biol 20(23):9009-9017.

Rogers JM. 2008. Tobacco and pregnancy: overview of exposures and effects. Birth Defects Res C Embryo Today 84(1):1-15.

Roseboom T, de Rooij S, Painter R, et al. 2006. The Dutch famine and its longterm consequences for adult health. Early Hum Dev 82(8):485-491.

Samuelsson AM, Ohrn I, Dahlgren J, et al. 2004. Prenatal exposure to interleukin-6 results in hypertension and increased hypothalamic-pituitaryadrenal axis activity in adult rats. Endocrinology 145(11):4897-4911.

Seckl JR. 2001. Glucocorticoid programming of the fetus; adult phenotypes and molecular mechanisms. Mol Cell Endocrinol 185(1-2):61-71.

Seckl JR, Meaney MJ. 2004. Glucocorticoid programming. Ann N Y Acad Sci 1032:63-84.

Silverman BL, Metzger BE, Cho NH, et al. 1995. Impaired glucose tolerance in adolescent offspring of diabetic mothers. Relationship to fetal hyperinsulinism. Diabetes Care 18(5):611-617.
Silverman BL, Rizzo T, Green OC, et al. 1991. Long-term prospective evaluation of offspring of diabetic mothers. Diabetes 40 Suppl 2:121-125.

Silverman BL, Rizzo TA, Cho NH, et al. 1998. Long-term effects of the intrauterine environment. The Northwestern University Diabetes in Pregnancy Center. Diabetes Care 21 Suppl 2:B142-B149.

Singh RR, Cullen-McEwen LA, Kett MM, et al. 2007. Prenatal corticosterone exposure results in altered AT1/AT2, nephron deficit and hypertension in the rat offspring. J Physiol 579(Pt 2):503-513.

Sloboda DM, Challis JR, Moss TJ, et al. 2005. Synthetic glucocorticoids: antenatal administration and long-term implications. Curr Pharm Des 11(11):1459-1472.

Somm E, Schwitzgebel VM, Vauthay DM, et al. 2009. Prenatal nicotine exposure and the programming of metabolic and cardiovascular disorders. Mol Cell Endocrinol 304(1-2):69-77.

Sugden MC, Holness MJ. 2002. Gender-specific programming of insulin secretion and action. J Endocrinol 175(3):757-767.

Sugden MC, Langdown ML, Munns MJ, et al. 2001. Maternal glucocorticoid treatment modulates placental leptin and leptin receptor expression and materno-fetal leptin physiology during late pregnancy, and elicits hypertension associated with hyperleptinaemia in the earlygrowth-retarded adult offspring. Eur J Endocrinol 145(4):529-539.

Takahashi LK, Kalin NH. 1991. Early developmental and temporal characteristics of stress-induced secretion of pituitary-adrenal hormones in prenatally stressed rat pups. Brain Res 558(1):75-78.

Takahashi LK, Turner JG, Kalin NH, et al. 1998. Prolonged stress-induced elevation in plasma corticosterone during pregnancy in the rat: implications for prenatal stress studies. Psychoneuroendocrinology 23(6):571-581.

Tamashiro KL, Terrillion CE, Hyun J, et al. 2009. Prenatal stress or highfat diet increases susceptibility to diet-induced obesity in rat offspring. Diabetes 58(5):1116-1125.

Tronche F, Kellendonk C, Kretz O, et al. 1999. Disruption of the glucocorticoid receptor gene in the nervous system results in reduced anxiety. Nat Genet 23(1):99-103.

Uno H, Eisele S, Sakai A, et al. 1994. Neurotoxicity of glucocorticoids in the primate brain. Horm Behav 28(4):336-348.

Vazquez DM. 1998. Stress and the developing limbic-hypothalamic-pituitary-adrenal axis. Psychoneuroendocrinology 23(7):663-700.

Weaver IC. 2009. Shaping adult phenotypes through early life environments. Birth Defects Res C Embryo Today 87(4):314-326.

Weaver IC, Cervoni N, Champagne FA, et al. 2004. Epigenetic programming by maternal behavior. Nat Neurosci 7(8):847-854.

Weaver IC, Champagne FA, Brown SE, et al. 2005. Reversal of maternal programming of stress responses in adult offspring through methyl supplementation: altering epigenetic marking later in life. J Neurosci 25(47):11045-11054.

Weaver IC, Meaney MJ, Szyf M, et al. 2006. Maternal care effects on the hippocampal transcriptome and anxiety-mediated behaviors in the offspring that are reversible in adulthood. Proc Natl Acad Sci U S A 103(9):3480-3485.

Wei Q, Lu XY, Liu L, et al. 2004. Glucocorticoid receptor overexpression in forebrain: a mouse model of increased emotional lability. Proc Natl Acad Sci U S A 101(32):11851-11856.

White PC, Mune T, Agarwal AK, et al. 1997. 11 beta-Hydroxysteroid dehydrogenase and the syndrome of apparent mineralocorticoid excess. Endocr Rev 18(1):135-156.

Woodall SM, Johnston BM, Breier BH, et al. 1996. Chronic maternal undernutrition in the rat leads to delayed postnatal growth and elevated blood pressure of offspring. Pediatr Res 40(3):438-443.

Woods LL. 2006. Maternal glucocorticoids and prenatal programming of hypertension. Am J Physiol Regul Integr Comp Physiol 291(4):R10691075.

Woods LL, Weeks DA. 2005. Prenatal programming of adult blood pressure: role of maternal corticosteroids. Am J Physiol Regul Integr Comp Physiol 289(4):R955-R962.

Woods LL, Weeks DA, Rasch R, et al. 2004. Programming of adult blood pressure by maternal protein restriction: role of nephrogenesis. Kidney Int 65(4):1339-1348.

Wu J, Song TB, Li YJ, et al. 2007. Prenatal restraint stress impairs learning and memory and hippocampal PKCbeta1 expression and translocation in offspring rats. Brain Res 1141:205-213.

Yogev Y, Visser GH. 2009. Obesity, gestational diabetes and pregnancy outcome. Semin Fetal Neonatal Med 14(2):77-84.

Zambrano E, Martinez-Samayoa PM, Bautista CJ, et al. 2005. Sex differences in transgenerational alterations of growth and metabolism in progeny (F2) of female offspring (F1) of rats fed a low protein diet during pregnancy and lactation. J Physiol 566(Pt 1):225-236.

Zarrow MX, Philpott JE, Denenberg VH, et al. 1970. Passage of 14C-4-corticosterone from the rat mother to the foetus and neonate. Nature 226(5250):1058-1059. 